\title{
Las Mujeres Mexicanas durante el gobierno de Lázaro Cárdenas, 1934-1940
}

\author{
The Mexican Women during the government of \\ Lázaro Cárdenas, 1934-1940 \\ As Mulheres Mexicanas durante o governo de \\ Lázaro Cárdenas, 1934-1940
}

\author{
Elvia Montes de Oca Navas ${ }^{1}$ \\ Integrante Sociedad de Historia de la Educación Latinoamericana - SHELA \\ Grupo de investigación HISULA - UPTC \\ elvia.montesdeoca@gmail.com
}

Recepción: 07/11/2013

Evaluación: 22/05/2014

Aceptación: 24/11/2014

Artículo de reflexión

\section{RESUMEN}

El presente documento aborda el tema de las mujeres en las primeras décadas del siglo $\mathrm{XX}$, especialmente durante el gobierno de Lázaro Cárdenas (1934-1940). La hipótesis central del trabajo es que si bien en las políticas gubernamentales $\mathrm{y}$ en algunos medios impresos, como lo fueron los periódicos y los libros escolares de la época del gobierno cardenista, se propusieron cambios en las condiciones sociales en las que vivían las mujeres y en sus relaciones con los varones, estas condiciones no cambiaron de manera estructural, y se reforzaron en el imaginario social. Demostrar esto fue el objetivo central del documento y para ello, como metodología, se hizo el análisis de algunas fuentes primarias de información, como son los periódicos y los libros escolares, y en la conclusión se refuerza la hipótesis planeada.

Palabras clave: Revista Historia de la Educación Latinoamericana, Estudios de género, Historia social, Condición social de las mujeres, Educación socialista.

1 Doctora en Estudios Latinoamericanos por la Facultad de Ciencias Políticas y Sociales de la Universidad Nacional Autónoma de México. Miembro activo de la Sociedad de Historia de la Educación Latinoamericana (SHELA), integrante del grupo de investigación HISULA adscrito a la Universidad Pedagógica y Tecnológica de Colombia, miembro de redes académicas mexicanas: Red de Historiadores de la Prensa y Red de Especialistas en Docencia, Difusión e Investigación en Enseñanza de la Historia. Este articulo es resultado del proyecto "La Universidad en la capacitación de maestras rurales SGI 1034" y "Las educadoras en las Escuelas Normales en Colombia SGI 1293" desarrollado por el grupo HISULA - UPTC. 


\section{ABSTRACT}

This paper addresses the issue of women in the early twentieth century, especially during the government of Lázaro Cárdenas (1934-1940). The central hypothesis of this paper is that even if the government policies and in some print media, such as the newspapers and textbooks at the Cardenas government time, proposed social conditions in relation how women lived and their relationships with men, these conditions did not change in a structural way, and they were reinforced by the social imaginary. The main objective of the document was to determine the hypothesis presented above and as a methodology there was the analysis of some primary sources of information, such as newspapers and textbooks, and in the conclusion it is reinforced the hypothesis planned.

Key words: History of Latin American Education Journal, gender studies, social history, social condition of women, socialist education.

\section{RESUMO}

O presente texto aborda o tema das mulheres nas primeiras décadas do século XX, especialmente durante o governo de Lázaro Cárdenas (1934-1940). A hipótese central do trabalho é que, ainda que nas políticas governamentais e em alguns meios impressos, como foram os jornais e os livros escolares da época do governo cardenista, se propuseram mudanças nas condições sociais na vida das mulheres e de suas relações com os homens, estas condições não foram transformadas de maneira estrutural, e foram reforçadas no imaginário social. Demonstrar isto foi o objetivo central deste texto, e para isso, como metodologia, fez-se análise de algumas fontes primárias de informação, como são os jornais e os livros escolares, e na conclusão se reforça a hipótese elaborada.

Palavras-chave: Revista Historia da Educação Latino-americana, estudos de gênero, história social, condição social das mulheres, educação socialista.

\title{
INTRODUCCIÓN
}

\author{
No es tan importante si la vida vale la pena \\ ser vivida, lo que vale la pena preguntarse es \\ si se desea vivir y en qué condiciones, ya que \\ el sentido no se devela, sino que se procrea, \\ se inventa, se forja y se obtiene. \\ Simone de Beauvoir.
}

"Las mujeres, a través de la historia de México, parecen objeto de un doble juego: sublimadas en el mito, en la sociedad participan siempre como un sujeto subordinado en razón de su biología"2. En la Revolución de 1910, no solo en los

2 Julia Tunón. Mujeres en México. Recordando una historia (México: Fondo de Cultura Económica, 2004 ), 18. 
momentos violentos, sino también más tarde en la reorganización del país en las siguientes décadas, algunas mujeres lucharon por el cambio de las relaciones entre hombres y mujeres; otras, "hay que decirlo, prefirieron la comodidad de lo conocido: al fin y al cabo la tradición feminista era reciente y el condicionamiento ideológico ancestral" ${ }^{3}$. Las mujeres del siglo XX, especialmente las de las primeras décadas, vivieron y padecieron las ambigüedades de un nuevo régimen social que no terminaba por nacer y otro que no terminaba por desaparecer, un sistema que hablaba de libertad, igualdad, ciudadanía, pero donde las mujeres seguían bajo la tutela de los varones, lo que daba por resultado una inequidad social contraria a los supuestos del liberalismo y la democracia que se dijo serían las ideas que guiarían al nuevo México del siglo XX.

Esta visión de subordinación la vivieron las mujeres mexicanas de las primeras décadas del siglo XX, reconocida como "propia de su sexo" y por ello "natural"; una "identidad femenina" que desde el hogar y a través de sus madres era construida en la infancia y para toda la vida, en un proceso de conformidad y autoaceptación de esta situación inequitativa y desigual.

La amenaza de que si las mujeres actuaban más allá de los límites de "su identidad" podría destruirlas como mujeres y de paso ser un mal ejemplo para las demás reforzó la idea de que había que separarlas, cercarlas o desprestigiarlas; el calificativo más usado para no hacerles caso es que estaban "locas", con todos los significados que esta palabra encierra.

A la llegada de Lázaro Cárdenas a la presidencia en 1934, los mexicanos, y especialmente las mexicanas, tuvieron esperanzas de que México sería dirigido al logro de un país más justo y equitativo social y económicamente hablando. Cárdenas se anunció a sí mismo como un presidente liberal y demócrata, que iba a encabezar un gobierno a favor de los más necesitados, incluidas las mujeres.

\section{El gobierno del presidente Lázaro Cárdenas (1934-1940)}

En este trabajo se analizan algunas de las políticas públicas establecidas desde el Estado mexicano a favor de la mejora de las condiciones sociales en las que vivían las mujeres de entonces, políticas difundidas a través de diversos medios, especialmente a través de textos escolares escritos para niños de educación elemental y para adultos analfabetas.

De acuerdo con las fuentes consultadas, el cardenismo no se propuso el cambio profundo de las relaciones sociales entre los sexos. Prueba de esto fue no haber

$3 \quad$ Ibíd., 156. 
otorgado el voto a las mujeres durante este período presidencial. El tema del voto universal de las mujeres desde el Ejecutivo federal se creyó resuelto en diciembre de 1937 cuando se aprobó la reforma al artículo 34 constitucional, en la que se reconoció y registró legalmente este derecho, pero dicha reforma quedó en suspenso pues no se publicó en el Diario Oficial. Esto "significa en la práctica un veto del Presidente de la República"4.

Durante el cardenismo se ofrecieron mejorar las relaciones sociales entre hombres y mujeres, de tal manera que las condiciones de subordinación de las mujeres fueran menos duras y difíciles, sin cambiar estructuralmente las relaciones sociales entre ellos. Sin embargo, esto significó ya un logro al fin y al cabo, sin alterar su situación de mujeres subordinadas a los varones, dedicadas especialmente a la reproducción y cuidado de la especie humana.

El Plan Sexenal, elaborado en 1933 por el Partido Nacional Revolucionario (PNR) comouna guía para el ejercicio del gobierno de Lázaro Cárdenas, habla de obreros, campesinos, ejidatarios, maestros y niños a quienes se les ofrecen esperanzas de una vida mejor, pero todo se habla en masculino, nada en femenino; soldados, hijos, alumnos, todos HOMBRES. Únicamente habla de las mujeres al referirse a la prostitución y a la mendicidad femeninas; no habla de lo mismo refiriéndose a los hombres, luego estas actividades se adjudican solo a las mujeres. Se dice que se harían campañas "para combatir las causas determinantes de la prostitución, a fin de evitar que esta constituya un medio de vida para la mujer; y para evitar la mendicidad profesional" ${ }^{\prime}$. Aunque no se lee claramente en el documento, de alguna manera se advierte que la prostitución femenina está ligada a la condición económica de las mujeres que la ejercen, ya no a que son "mujeres malas por naturaleza"; esto es ya un avance en el imaginario social, al comparar con las décadas anteriores cuando las "mujeres malas" lo eran por su propia naturaleza ligada al mal. Aquí se reconoce ya que son causas económicas las que fundamentalmente llevan a las mujeres a la prostitución, aunque se cuida mucho el uso de juicios universales.

Durante el cardenismo a las mujeres se les abrieron nuevas opciones de trabajo: las fábricas, las escuelas, las parcelas mismas. El Estado se comprometió a mejorar su situación dentro de la sociedad desigual en la que vivían, siempre y cuando participaran activa y comprometidamente en la sociedad en construcción que se avisaba en esos días.

4 Silvia González Marín. Prensa y poder político. La elección presidencial en 1940 en la prensa mexicana. (México: Universidad Nacional Autónoma de México/ Siglo xxi Editores, 2006), 327.

5 Partido Nacional Revolucionario. Plan Sexenal del Partido Nacional Revolucionario (México: Partido Nacional Revolucionario, 1937), 56. 
Si bien durante el cardenismo se apoyaron las organizaciones de las mujeres para hacer efectivas sus peticiones, ellas fueron organizadas por el gobierno mismo, que se encargó de incluirlas en las políticas públicas y en el partido oficial. A las mujeres se les incorporó en el mundo de lo público, se les sacó de sus casas sin dejar de seguir siendo responsables de ellas, pero en ambos mundos, el público y el privado, conservaron su condición de subalternas.

En el periódico El Nacional (México, D. F., 4 de septiembre de 1936), el presidente del Comité Ejecutivo Nacional del PRN, Silvano Barba González, publicó un "Manifiesto del PRN", en el que se lee:

El Comité Ejecutivo reconoce en la mujer trabajadora organizada, un factor social cuyas capacidades deben estimularse para que ella alcance nivel igual al de los elementos varones en la lucha sindical y en el ejercicio de los derechos políticos, fundándose en el principio reconocido por la legislación del trabajo que no establece distinciones por razones de sexo entre los componentes del proletariado. El Partido está vivamente interesado en lograr la emancipación de la mujer, no sólo en la vida política, sino también en el campo de la lucha económica. Promoverá, en consecuencia, la creación de organizaciones femeniles de tendencia revolucionaria; estimulará su desarrollo, y les ofrecerá todas las facilidades posibles para que extiendan su radio de acción en la República y para que logren cada día mayores reivindicaciones.

Las mujeres - en el documento se habla de la mujer- laboralmente ya fueron reconocidas como factores importantes de la economía y la producción nacional. Sin embargo, el corporativismo que reinó durante el cardenismo se hizo manifiesto aquí al hablar de las mujeres agrupadas en "organizaciones femeniles", integradas por mujeres organizadas por el propio gobierno y a iniciativa de él.

En los mensajes que el presidente Cárdenas enviaba a la sociedad mexicana, tanto en su calidad de candidato a la presidencia por el PNR como después, ya siendo presidente, hablaba de que se protegería a los niños, los ancianos, los desvalidos y las mujeres, todavía consideradas ésta como seres débiles que necesitaban de la protección y el cuidado de los gobernantes y las leyes. Cárdenas afirmaba en sus discursos que las mujeres campesinas y obreras serían rescatadas de su ignorancia gracias a la escuela, lo mismo que los hombres. Se refería principalmente a los hombres y a las mujeres adultos que no sabían leer y escribir, a quienes se les alfabetizaría, pero además, y muy importante, se les daría lo que hoy se conoce como educación cívica: se les informaría lo necesario para reafirmar su calidad de ciudadanos mexicanos libres e iguales.

Las mujeres, desde sus hogares tanto urbanos como rurales, más las del campo, donde sus condiciones de vida eran más pobres, se organizarían en 
grupos femeninos y se encargarían de llevar a cabo campañas antialcohólicas, mejoramiento de las condiciones de vida de sus hogares: alimentación, vestido, higiene, mejoramiento de las condiciones de salubridad del hogar y sus comunidades, plantación de árboles y plantas de ornato en la casa y en la comunidad, cría de animales para el consumo doméstico, organización de festivales y actos públicos. Se les reconoció como agentes económicos al hablar de la posibilidad de organizarse en cooperativas de producción y de consumo, comprando las mercancías en volúmenes más grandes para ser distribuidas entre las cooperativistas, asegurándose así un ahorro, y también en cooperativas para la producción y venta de productos.

El mismo Cárdenas reconocía en sus discursos la importancia que las mujeres podían tener en la economía familiar, siempre y cuando estuvieran organizadas en grupos. Organizarse en cooperativas "que sirvan para la liberación económica de la mujer [...] Así preparada la mujer, cumple con más amplitud sus altos fines en el seno del hogar y sus funciones como factor del progreso social"6. Las mujeres siguieron siendo vistas como responsables de su hogar, pero ahora también como colaboradoras en los ingresos de la familia.

El presidente Cárdenas reconoció las difíciles condiciones de trabajo en las que vivían las mujeres en sus hogares, especialmente las del campo; por eso había que mejorar esas condiciones domésticas, haciéndolas más llevaderas, no a través de la inclusión plena de las mujeres en la vida económica, social y política del país, sino gracias a los avances de la tecnología moderna. En un discurso que el presidente Cárdenas pronunció en Oaxaca dijo:

Un detalle que para muchas gentes es intrascendente, pero que sí representa grandes esfuerzos en la vida de la mujer campesina, es la de verse sometida a las grandes tareas del metate; y es obligación de todos, interesarse para liberarla de este esfuerzo agobiante. Debemos organizar las cooperativas femeninas y dotar de molinos a todas aquéllas que, por su difícil condición económica, no estén en condiciones de adquirirlos, en la inteligencia de que con la instalación del molino y aprovechando el motor, podrá tener el poblado su alumbrado y bombear agua para sus servicios urbanos?

El uso de recursos y aparatos modernos llegaría a los pueblos pobres: molinos, luz, agua potable. Las mujeres fueron vistas como seres humanos explotados no solo por los más poderosos económicamente hablando, igual que sus compañeros, sino además por las condiciones de atraso en las que vivían dentro de sus casas, y que hacían más difícil cumplir con sus labores como esposas y madres.

6 Lázaro Cárdenas. El Nacional. México, 8 de diciembre de 1936.

7 Lázaro Cárdenas. El Nacional. México, 27 de marzo de 1937. 
Cárdenas ofreció también:

Darle representación a la mujer en la directiva nacional [de los campesinos] por medio de una secretaría que lleve a cabo la organización nacional de las mujeres campesinas, que con actitud ejemplar han venido desarrollando una acción muy trascendente y meritoria en los aspectos: educativo, organización del trabajo, eliminación de centros de vicio, organización de cooperativas de producción y de consumo y en otras muchas actividades que las hace acreedoras a que se piense y se apoye de una manera leal y decidida su completa reivindicación ${ }^{8}$.

Diversas mujeres supieron y pudieron aprovechar este ambiente de apertura y oportunidad para ellas. Amalia González Caballero de Castillo Ledón en 1939 llegó a la Comisión Interamericana de Mujeres en representación del gobierno mexicano. Se propuso defender los principios democráticos de las mujeres, la igualdad entre los géneros, y de 1934 a 1948 fue presidenta del Ateneo de las Mujeres.

Entre 1935 y 1938 existió el Frente Único Pro Derechos de la Mujer, que agrupó a mujeres obreras, de clase media y alta de diferentes zonas del país, hasta alcanzar las 50.000 participantes ${ }^{9}$. Como activistas sobresalen Refugio García, Esther Chapa, Juana Belén Gutiérrez de Mendoza, Soledad Orozco, Adelina Zendejas, Frida Kahlo y Concha Michel: mujeres que lucharon por mejores posiciones en los trabajos, lo mismo que por sus salarios, el derecho al voto y el respeto por las diferencias de género. Este frente desapareció como tal al término del gobierno cardenista y después pasó a ser parte de la política oficial, pero al menos ya hubo intentos importantes de organizaciones femeninas en defensa de los derechos de las mujeres.

En el periódico El Nacional (7 de junio de 1935) apareció publicado “El programa de estudios y de acción de la escuela socialista", órgano rector de la reforma que había instaurado la educación socialista en México durante el gobierno de Lázaro Cárdenas.

La nueva educación socialista, según este documento, sería obligatoria, gratuita, de asistencia infantil, única, coeducativa, práctica, integral, progresiva, científica, desfanatizante, orientadora, de trabajo, cooperativista, emancipadora:

porque enaltece al niño, a la mujer y a las clases productoras y desposeídas; porque señala los medios adecuados para obtener la liberación de los prejuicios de orden

8 Lázaro Cárdenas. El Nacional. México, 29 de agosto de 1938.

9 Julia Tuñón. Mujeres en México. Recordando una historia, op. cit., 170. 
económico, social, político y religioso, y porque tiende a destruir toda clase de vicios y formas de explotación humana de la sociedad actual ${ }^{10}$.

La educación, en este caso la elemental, sería responsabilidad del Estado, encarnado en el gobierno, y estaría dirigida a preparar a las nuevas generaciones en la lucha por el advenimiento de un régimen social sin explotados, "una escuela socializada que no estuviera al margen de la vida y de la sociedad, sino que combatiera sus lacras y actuara en defensa de las clases desposeídas"11. Crearía un nuevo tipo de mexicanos con ideales dirigidos a el logro de una sociedad más justa e igual.

La educación fue vista como un servicio social y un derecho otorgado por el Estado con "la tarea de despertar en las generaciones jóvenes un espíritu amplio de solidaridad humana, una actitud más firme por cuanto a la función social de la cultura, y una conciencia más clara y científica sobre la posición del hombre en el Cosmos y en la Sociedad"12.

Estas oportunidades que se abrieron en la educación de las mujeres y los hombres, especialmente los más necesitados, fueron aprovechadas por diversas mujeres que sobresalieron en la vida académica de esos años y de años posteriores. Desde la década de 1930-1940 sobresalen varias mujeres en la academia: por ejemplo, Soledad Anaya Solórzano en la Facultad de Filosofía y Letras de la Universidad Nacional Autónoma de México (UNAM); Rosario Castellanos, maestra en filosofía graduada en la misma universidad con su tesis Sobre la cultura femenina, en la que reflexiona sobre las contribuciones de las mujeres a la cultura, y su posición marginal dentro de ella; Luz Vera, doctorada en filosofía en la UNAM; Palma Guillén, en la Escuela Nacional de Maestros, fue enviada extraordinaria y ministra plenipotenciaria de México en Colombia en 1935; Concha Urquiza, poeta que en su juventud perteneció al Partido Comunista antes de su reconversión religiosa en 1937 y quien publicó la revista literaria Ábside; Eulalia Guzmán, Concha Méndez, Paula Gómez Alonso, y la lista puede continuar con mujeres sobresalientes en la academia y en la diplomacia.

La educación impartida por el Estado sería la misma tanto en el medio urbano como en el rural, orientada una hacia las actividades productivas desarrolladas en las ciudades y otra hacia las actividades del campo. También sería igual para niños que para niñas, para hombres que para mujeres; por eso todas las escuelas serían mixtas.

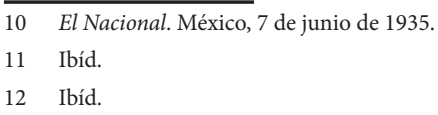


La coeducación impuesta en las escuelas dependientes del gobierno provocó rechazos en algunos sectores sociales, especialmente en los urbanos, entre los miembros del clero católico y entre muchas mujeres. La coeducación en las escuelas, la presencia de niños y niñas juntos, causó desconfianza no solo entre los padres de familia, sino también entre los maestros, especialmente entre las maestras, al ser considerada como la causa futura de un grave desequilibrio social pues arriesgaba el "carácter femenino" de las niñas y la "virilidad y masculinidad" de los niños. Para convencer a los mexicanos de las bondades de la coeducación, en el Programa se dijo que ayudaría a:

facilitar las relaciones normales entre hombres y mujeres, combatiendo los obstáculos y prejuicios que se originan en su mayor parte por la separación innecesaria de niños y niñas en las escuelas. Sirve además para ofrecer iguales oportunidades de capacitación económica, intelectual y social al hombre y a la mujer ${ }^{13}$.

Los niños y las niñas serían educados juntos en las escuelas pero se "procurará, igualmente, que no se desvirtúen las características propias de su sexo"14. Los usos y las costumbres de la época tuvieron un peso importante en las políticas públicas del momento; de ahí el cuidado que se tuvo en el alcance y profundidad de los cambios sociales que se proponían.

\section{Los libros escolares}

Una de las medidas llevadas a cabo por el gobierno cardenista para poner en práctica la educación socialista fue la edición de nuevos textos escolares. Unos libros fueron hechos por una comisión editora de la Secretaría de Educación Pública (SEP), nombrada por el mismo gobierno; otros fueron hechos por particulares pero aprobados por la misma SEP, siempre y cuando estuvieran apegados a los lineamientos de la reforma educativa puesta en marcha.

En los libros escolares de lectura se abrieron nuevos mundos imaginarios y posibles de alcanzar gracias al trabajo de los trabajadores, los niños, las mujeres y por supuesto el gobierno, trabajando todos en un proyecto de nación más justa y equitativa no solo entre las clases sociales, sino también entre los géneros.

En los libros utilizados en las escuelas del cardenismo, la escuela fue considerada como un espacio en el que se crea y recrea el imaginario colectivo de lo que significaba "ser mujer" y "ser hombre". Surgieron nuevos sujetos sociales que "hablan" y que antes permanecían "callados": niños, obreros, campesinos, indígenas, mujeres.

13 Ibíd.

14 Ibíd.

Rev. hist.educ.latinoam - Vol. 17 No. 24, enero - junio 2015 - ISSN 0122-7238 - pp. 149 - 166 
Los libros escolares fueron hechos conforme a los lineamientos pedagógicos, científicos, culturales e ideológicos de la educación socialista. Incluyen imágenes muy sencillas, casi lineales y en colores blanco y negro; presentan escenas escolares donde niños y niñas están juntos, de acuerdo con la coeducación que se dijo que era obligatoria para todas las escuelas; no obstante, los alumnos se ven sentados en el salón de clases en filas separadas por sexos, no están mezclados. Sin embargo esto ya fue una novedad, especialmente en las ciudades donde hubo mayor resistencia a esta reforma, pero aún así, en las imágenes de los libros niños y niñas aparecen separados dentro del salón de clases.

En los libros los niños y las niñas se llaman entre sí "camaradas". Tanto las imágenes como las lecciones de los libros analizados - libros de lectura escritos para las escuelas rurales: Simiente, y para las urbanas: Escuela Socialistafomentan valores considerados como fundamentales para la formación del buen ciudadano: respeto a los mayores, los padres, los maestros y los animales, amor al trabajo, responsabilidad en el cumplimiento de los compromisos contraídos, participación en las tareas familiares, escolares y comunales; de esto se encargaban especialmente las mujeres en el hogar y los maestros en la escuela. Veamos un ejemplo sobre el respeto a los animales: "Robar un pichón del nido, es un delito tan grave como robar un niño de su cuna"15. Esto le dijo una madre a un niño que quería robar un pichón de su nido.

Las mascotas de niños y niñas son diferentes: generalmente la de los niños es un perro, bravo guardián del hogar; la de las niñas es un gato, casi siempre en posición pasiva y durmiendo. ¿Dice esto algo con respecto a lo que significaba ser niño o niña, de acuerdo con las costumbres e ideas de la época?

Según las lecciones de estos libros, niños y niñas participaban juntos en las cooperativas, la cría de animales y los talleres, todos trabajando en situaciones iguales y en actividades libremente elegidas por los alumnos; la condición era colaborar independientemente de los sexos de los niños, fomentando así, desde la niñez, la igualdad entre hombres y mujeres. "Nuestra escuela parece una colmena en donde no hay zánganos que se aprovechen del esfuerzo de los demás"16.

En los libros escolares aparecen mujeres trabajando no solo en la casa, sino también en la cría de animales domésticos pero ya en condiciones avanzadas y con métodos modernos, como es el uso de vacunas aplicadas a cerdos y gallinas. Sin embargo, el lugar de las mujeres del campo sigue siendo la casa: lavando, cosiendo, cuidando de los niños, más si estaban enfermos.

15 Gabriel Lucio. Simiente, Libro tercero (México: Secretaría de Educación Pública, 1939), 19.

16 Ibíd., 41. 
El día en que los campesinos estén perfectamente unificados, el Himno del Trabajo entonado por los hombres en las sementeras, por las mujeres en el hogar y por los niños en la escuela, pregonará la aparición de una era próspera y fecunda para los trabajadores del campo $^{17}$.

En estos libros se ve a las mujeres que llevan a los niños a la escuela. En el caso de los libros para escuelas rurales, a los hombres se les ve trabajando en el campo, y en el caso de los libros para escuelas urbanas lo hacen en las fábricas; en éstas se ve a los trabajadores en asambleas sindicales, entre las cuales ya aparecen algunas mujeres. En ambos tipos de libros aparecen maestras, considerada esta profesión, desde tiempo atrás, como una carrera "propia para mujeres" y su condición de madres. "La maestra es muy cariñosa; trata a sus alumnos como una madre"18.

De los trabajos del campo el papá regresa fatigado, la niña lo espera en la puerta. "Juntos y felices entran en el hogar, donde la madre les espera con la apetitosa cena ya servida en la mesa"19. Según la imagen del libro, en una cabecera de la mesa aparece sentado el padre, en la otra el hijo y al lado la hija; la madre está ausente, seguramente ella está ocupada en hacer y servir los alimentos.

En las lecturas se ensalza a la mujer como ama de casa que no descansa, dedicada todo el día a los quehaceres domésticos:

Mamá no sale.

Mamá está en la casa.

Ella cose y lava.

Ella sacude las cosas.

Mamá cuida de todo en la casa.

¡Tan buena mamaíta! ${ }^{20}$

En cambio, "Don Benito [el padre] es campesino trabajador; tiene una parcela que trabaja con empeño" 21 .

En los libros, los niños hijos de campesinos quieren crecer pronto para ayudar a sus padres en las labores del campo, lo mismo que los niños de los obreros quieren también ser obreros cuando sean grandes:

\footnotetext{
17 Ibíd., 110.

18 Gabriel Lucio. Simiente, Libro primero (México: Secretaría de educación Pública, 1935), 45.

19 Ibíd., 30.

20 Secretaría de Educación Pública. Escuela Socialista, Primer Año (México: Secretaría de Educación Pública, 1938 ), 30.

21 Gabriel Lucio. Simiente, Libro primero, op. cit., 42.
} 
Mamá:

Quiero ser obrero,

quiero ser obrero

como mi papá ${ }^{22}$

Así le dice a su madre un niño que cursa el primer año de educación elemental.

"Cuando sea grande trabajaré en lugar de mi padre, para que él descanse" 23 . Así habla un niño campesino de segundo año. Los esquemas paternos, en este caso las actividades productivas de campesinos y obreros, son copiados por los niños, quienes de grandes quieren ser lo mismo que sus padres. De este modo se plantea una reproducción social en la que, si bien se ofrecen mejores condiciones de vida material para las clases trabajadoras: campesinos y obreros, sigue siendo difícil en esos años el logro de una verdadera movilidad social.

Con respecto a las mujeres en el campo, en el libro Simiente de cuarto año aparece una lección titulada "La liberación de la mujer campesina":

¡Pobres mujeres campesinas! Inclinadas sobre el metate desde antes que despunte el alba, hasta la noche, gastan todas sus fuerzas en piezas que tal vez sirvan de cocina, comedor y dormitorio; en piezas donde el humo, desprendiéndose del primitivo hogar de tres piedras [tlecuil], entre los cuales chisporrotea el fuego, vicia el aire haciéndose malsano para la respiración.

Se agrega que estas mujeres no tienen tiempo libre, por ejemplo, "para una buena lectura"; de ahí la necesidad de que se le "libere de un género de vida que la humilla". Era necesario enseñar a las mujeres a modificar su forma de vida, especializar el uso de las habitaciones de la casa: cocina, comedor, dormitorio; levantar el fuego del suelo a su altura, utilizar carbón u otros recursos en lugar de leña, un molino que sustituyera al metate; estos y otros adelantos modernos más harían menos penosas las tareas de las mujeres campesinas. "Estos cambios harán hogares campesinos risueños, en que la mujer, ya liberada, pueda dedicarse contenta a las faenas caseras y a la importantísima tarea de criar y educar a sus hijos" 24 .

Las familias mexicanas más humildes debían vivir en mejores condiciones. Por ello había que educar especialmente a las mujeres y poner a su alcance los conocimientos necesarios que les permitieran formas de vida más confortables y

22 Secretaría de Educación Pública. Escuela Socialista, Primer Año, op. cit., 69.

23 Gabriel Lucio. Simiente, Libro segundo (México: Secretaría de Educación Pública, 1939), 8.

24 Gabriel Lucio. Simiente, Libro cuarto (México: Secretaría de Educación Pública, 1935), 56. 
con ello menos difíciles, pues ellas eran las encargadas del bienestar y educación de la familia toda, especialmente de sus hijos.

En el imaginario de los niños contenidos en los libros están el "padre trabajador y responsable" y "la madre siempre ocupada en el hogar". Las niñas ayudan a sus mamás en las labores de la casa cuando no están en la escuela. En las imágenes se les ve alegres y risueñas con la escoba en las manos o cuidando de sus hermanos menores, mientras las madres se dedican a otros quehaceres domésticos.

Además, la profesora de 1er. año semanariamente congrega a las mujeres para enseñarles cosas muy útiles respecto de la preparación de alimentos nutritivos, modo de cortar y coser las prendas de vestir, cuidados que deben tener en la crianza de los niños, y maneras de ejecutar los demás trabajos domésticos. ${ }^{25}$

Así las mujeres estarían más preparadas para ser mejores madres y esposas.

En los libros de lectura para las escuelas urbanas se hace más evidente la ideología de la educación socialista. En los libros Simiente, el campo y sus moradores aparecen un tanto idealizados, viviendo una vida tranquila y feliz, sin dejar de ser injustas las condiciones de trabajo de los campesinos, que poco a poco se va mejorando gracias, en buena medida, al reparto de ejidos que hizo con mayor intensidad el gobierno cardenista. En los libros para las escuelas urbanas la ciudad no es vista de manera idílica; en ella se presentan más marcadas las diferencias sociales, la explotación de los trabajadores y la miseria en la que vivían las clases más bajas. Sin embargo, había esperanza para los trabajadores en la defensa y reclamo de sus derechos laborales, con base en su organización en sindicatos y su afiliación al partido oficial.

Los niños, protagonistas de los libros de lectura para escuelas urbanas, no son niños felices, sino hijos de obreros pobres y esposas aún más pobres, que antes de ir a la escuela tenían que trabajar, por ejemplo, vendiendo periódicos; en las imágenes se les ve caminando por las calles de la ciudad, dándose cuenta de las injustas y desiguales condiciones de vida que hay en ella, especialmente al referirse a los trabajadores y sus familias.

Se habla de la explotación de los obreros en las fábricas y la esperanza por la venida de un mundo mejor. A las niñas y los niños, igual que los hombres y las mujeres, se les observa participando en asambleas, opinando y decidiendo sobre la solución de sus problemas. "¿Y la obrera? La obrera está también aquí, al lado

25 Ibíd., 91. 
de su compañero, o en los jardines de recreación al lado de sus niños, o en los museos de higiene recibiendo útiles instrucciones" ${ }^{26}$. En los libros escolares de lectura para las escuelas urbanas ya se habla de guarderías para los hijos de las obreras como anexos de las fábricas. Esto es ya un importante adelanto en la sociedad mexicana de esos años, en atención a la condición laboral de las mujeres y la necesidad de cuidar de sus hijos mientras ellas trabajaban, especialmente como obreras. Las mujeres ya no están solo ocupadas en las labores domésticas, o trabajando solo como enfermeras, maestras o secretarias como en los tiempos anteriores.

Otro libro de lectura para niños fue escrito por el profesor Rafael Ramírez: Plan sexenal infantil. En él se hace hincapié de manera insistente en la organización escolar de niños y niñas y en la igualdad que debía existir entre ellos. Los niños de este texto escolar viven en una comunidad llamada "Porvenir", sugerente el nombre. En ella existe una escuela unitaria, al frente hay un solo maestro que atiende grados escolares diversos y niños y niñas de distintas edades. Los niños y las niñas hacen sus planes de trabajo, en grupo lo discuten, nombran, acuerdan decisiones y tareas, registran resultados, todo en grupo; todos son "camaradas". A pesar de que los patrones masculino y femenino se conservan, ya existe una incipiente crítica a la situación de las mujeres:

Nuestros papás salen temprano a sus labores para ganar el sustento de toda la familia y nuestras mamás se quedan en casa ahogándose dentro de un mar de trabajo enorme. El otro día leí, no recuerdo dónde, que la mamá es el alma de la casa. Ella es la guardiana del hogar, la ejecutora de todas las tareas domésticas y la que cría y educa a las criaturas ${ }^{27}$.

En los contenidos de las lecciones de este libro hay el propósito de integrar por igual a niños y niñas en las labores realizadas en la escuela, las casas y la comunidad toda, pero respetando las labores "propias de cada sexo"; se dice que todo es posible "dentro de las reglas establecidas".

En el Libro de lectura para uso de las escuelas nocturnas para trabajadores, 1er. Grado se dice: "Soldados, obreros y campesinos: el nuevo Ejército de la Revolución". ¿Y las mujeres? El libro mismo responde que ellas están "atareadas cociendo las tortillas alrededor de las fogatas..."28. En este libro las imágenes de las mujeres no cambiaron mucho.

\footnotetext{
26 Secretaría de Educación Pública. Escuela Socialista, Quinto Año (México: Secretaría de Educación Pública, 1939), 215.

27 Rafael Ramírez. Plan Sexenal Infantil. Libro de lectura para el ciclo intermedio de las escuelas rurales (México: Biblioteca Cuauhtémoc, 1937), 48.

28 Secretaría de Educación Pública. Libro de lectura para uso de las escuelas nocturnas para trabajadores, 1er. Grado (México: Secretaría de Educación Pública, 1938), 79.
} 
Sin embargo, los contenidos de estos mensajes podrían tener por lo menos dos efectos principales: uno sería confirmar los roles sociales de los hombres y las mujeres con base en la tradición y las costumbres, pero el otro, y más interesante para su estudio, podría ser llamar la atención de los lectores de estos libros sobre la desigual condición social de las mujeres.

Al interior del hogar, la imagen que presentan los libros analizados de lo que "deben ser" las mujeres y lo que "deben ser" los hombres es muy semejante a la tradicional: la mujer en su casa encargada de los cuidados de la familia, y el hombre en el trabajo ganando lo necesario para mantener a sus hijos y a su compañera. Mujeres limpias, calladas, sumisas, trabajadoras, igual que las niñas; hombres osados, valientes, activos, creadores, propositivos, participativos, igual que los niños.

\section{CONCLUSIÓN}

El discurso de libertad e igualdad que se utilizó durante el cardenismo fortaleció ciertos espacios de autonomía en las mujeres en su lucha por el respeto a la libertad de los individuos, a favor de la equidad entre los géneros con base en las desigualdades reales, y contra la percepción y el aprendizaje inducidos de un orden "natural" de las relaciones entre los géneros, a partir de las diferencias sexuales.

Las imágenes contenidas en las fuentes utilizadas corresponden a la época de estudio y son reforzadas por diversos medios además de los aquí analizados: el cine, la radio, además de la Iglesia católica, que tenía un peso importante en el pensar y hacer de los mexicanos de esa época.

Sin embargo, la llegada de un gobierno cuyo presidente se declaró abiertamente a favor de los sectores sociales más necesitados, donde las ofertas de trabajo se ampliaron tanto en el campo como en la ciudad, debido especialmente al reparto de tierras que se hizo a los campesinos durante el cardenismo y a la demanda de trabajo que hubo en esos años en la producción de artículos no solo para el consumo interno, sino también para la exportación, especialmente para los Estados Unidos de América, dada la ampliación de su mercado ante la inminente Segunda Guerra Mundial, todo esto y más abrió a las mujeres nuevas posibilidades de trabajo asalariado y con ello la posibilidad de vivir en mejores condiciones. 
A pesar de esto, las políticas públicas desarrolladas durante el cardenismo en México respecto a las condiciones sociales de las mujeres siguieron siendo un tanto conservadoras respecto a los roles masculinos y femeninos resguardados a través de las ideas, las tradiciones y las costumbres, aunque ya aparecieron algunos rasgos de mayor justicia social no solo entre los sectores sociales, sino también entre hombres y mujeres.

Con respecto a los niños sobre los que se escribe en los documentos oficiales y en los libros escolares analizados aquí, son niños en los cuales se trató de cultivar valores que los hacían seres humanos más preocupados por su entorno y su comunidad, menos individualistas, más participativos y responsables, defensores de la igualdad entre sus semejantes; se les fomentaba el respeto por la naturaleza, el rechazo a los vicios y la vagancia, el respeto a los mayores, especialmente padres y maestros, el amor al trabajo y al compromiso, todos luchando desde su sitio por el logro de una sociedad mejor y con mayor igualdad entre hombres y mujeres.

La inserción de las mujeres en los trabajos asalariados fuera de sus hogares, además de cumplir con las responsabilidades y los trabajos del hogar y de la familia, estos últimos no reconocidos como tales y por lo tanto considerados como "gratuitos", amplió sus horizontes, sin perder su papel tradicional en el hogar como fundamento de la familia.

Según las políticas de la época, no se trataba de que las mujeres abandonaran lo privado por lo público, sino de lograr mejores condiciones de cooperación e igualdad entre los géneros, y para ello la educación podía funcionar como un medio para ampliar las fronteras del mundo y sus múltiples interpretaciones.

Un elemento indispensable para acabar con los esquemas de exclusión, subordinación y discriminación es saber y reconocer que estos esquemas sociales se desarrollan en contextos históricos identificables y por ello modificables; reconocer la evolución de estos esquemas, de ahí su historicidad.

En este sentido, la historia puede hacer algo: encender la memoria, ofrecer un espejo y no un espejismo, rescatar sueños y realidades pasados que ayuden a las mujeres a escapar del silencio. Sólo si existe un pasado se puede aspirar al futuro; por eso, para trabajar en el cambio, es fundamental entrar a la historia: es otra manera de entrar a la vida ${ }^{29}$.

29 Julia Tuñón. Mujeres en México. Recordando una historia, op. cit., p. 193. 
Conocemos la historia en partes, en pedazos, y los historiadores, resultado de nuestro tiempo, pretendemos rehacerla e interpretarla como un todo; sin embargo, no dejamos de ir más allá de nuestro presente y regresamos constantemente al pasado.

\section{FUENTES}

El Nacional. México, D. F., 1934-1940.

González Marín, Silvia. Prensa y poder político. La elección presidencial en 1940 en la prensa mexicana. México: Universidad Nacional Autónoma de México/ Siglo XXI Editores, 2006.

Partido Nacional Revolucionario. Plan sexenal del Partido Nacional Revolucionario. México: Partido Nacional Revolucionario, 1937.

Robles, Martha. Mujeres del siglo XX. México: Fondo de Cultura Económica, 2005.

Tuñón, Julia. Mujeres en México. Recordando una historia. México: Consejo Nacional para la Cultura y las Artes / Instituto Nacional de Antropología e Historia, 2004.

\section{REFERENCIAS}

Lucio, Gabriel. Simiente. Libro primero para escuelas rurales. México: Secretaría de Educación Pública, Comisión Editora Popular, 1935.

Lucio, Gabriel. Simiente. Libro segundo para las escuelas rurales. (5a. Ed.). México: Secretaría de Educación Pública, Comisión Editora Popular. 1939.

Lucio, Gabriel. Simiente. Libro tercero para escuelas rurales. (5 ${ }^{a}$. Ed.). México: Secretaría de Educación Pública, Comisión Editora Popular, 1939.

Lucio, Gabriel. Simiente. Libro cuarto para escuelas rurales. México: Secretaría de Educación Pública, Comisión Editora Popular, 1935.

Ramírez, Rafael. Plan sexenal infantil. Libro de lectura para el ciclo intermedio de las escuelas rurales. México: Biblioteca Cuauhtémoc, 1937. 
Secretaría de Educación Pública. Primer Año. Serie "S.E.P". Lectura oral. Escuela Socialista. México: Comisión Editora Popular de la Secretaría de Educación Pública, 1938.

Secretaría de Educación Pública. Quinto Año. Serie "S.E.P". Lectura oral. Escuela Socialista. México: Comisión Editora Popular de la Secretaría de Educación Pública, 1939.

Secretaría de Educación Pública. Libro de lectura para uso de las escuelas nocturnas para trabajadores. 1er. Grado. Serie "S.E.P". México: Comisión Editora Popular de la Secretaría de Educación Pública, 1939.

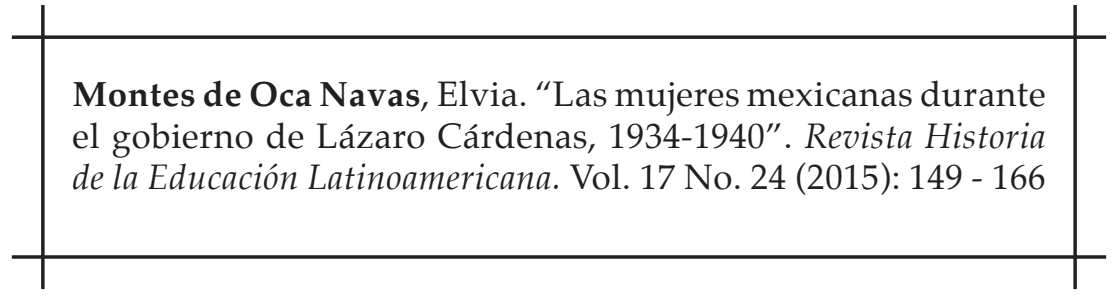

